\title{
Cutaneous endometriosis
}

\section{Endometriose cutânea}

\begin{abstract}
BURAK KAYA ${ }^{1}$
Emrah Aslan ${ }^{2}$

Cem Cerkez ${ }^{2}$

Gulsah Kaygusuz ${ }^{3}$

SAVAS SEREL ${ }^{4}$

This study was performed at the Department of Plastic, Reconstructive, and Aesthetic Surgery, Faculty of Medicine, Ankara University, Ankara, Turkey.

Submitted to SGP (Sistema de Gestão de Publicações/Manager Publications System) of RBCP (Revista Brasileira de Cirurgia Plástica/Brazilian Journal of Plastic Surgery).
\end{abstract}

Article received: August 15, 2012 Article accepted: September 3, 2012

\begin{abstract}
Endometriosis is defined as the presence of endometrial glands and stroma outside the uterine cavity. This disease is commonly observed in women, particularly those of reproductive age. The pelvis is the most common location for endometriosis. On the other hand, extrapelvic endometriosis, which is less common, is more difficult to diagnose because of the extreme differences in its presentation. In this article, we describe our experience of a case of endometriosis in an abdominal wall scar.
\end{abstract}

Keywords: Endometriosis. Skin abnormalities. Cicatrix/complications. Abdominal wall.

\section{RESUMO}

A endometriose é definida como a presença de glândulas endometriais e estroma fora da cavidade uterina. Essa doença, comum nas mulheres, é geralmente observada durante os anos reprodutivos. Embora a pelve seja o sítio mais comum da endometriose em mulheres, a localização extrapélvica é menos frequente e ainda mais difícil de diagnosticar, em decorrência das apresentações distintas. Neste artigo é descrito um caso de endometriose de cicatriz da parede abdominal.

Descritores: Endometriose. Anormalidades da pele. Cicatriz/complicações. Parede abdominal.

\section{INTRODUCTION}

Endometriosis is defined as the presence of endometrial glands and stroma outside the uterine cavity. This condition is commonly observed in women, particularly those of reproductive age; it has been estimated that endometriosis occurs in nearly $6-10 \%$ of women ${ }^{1}$.

The pelvis is the most common location of the disease, resulting in the common presenting symptoms of pelvic pain, dysmenorrhea, dyspareunia, cyclical bowel or bladder symptoms, and infertility. On the other hand, extrapelvic endometriosis, which is less common, is more difficult to diagnose because of the extreme differences in its presentation. Cutaneous endometriosis is one of the possible extrapelvic types of the disease, but physician ignorance on the subject often results in the diagnosis being delayed or missed. Cutaneous endometriosis involving the abdominal wall is rare. During preoperative diagnosis, cutaneous endometriosis can be easily mistaken for a suture granuloma, lipoma, abscess, cyst, or hernia ${ }^{2}$.

The differential diagnosis of a skin lesion on the abdominal wall is important because of the possibility that it is malignant. The majority of reported abdominal wall endometriomas have been noted in and adjacent to scars resulting from cesarean section. Primary cutaneous endometriosis has also been documented. The incidence of cesarean scar endometriosis is between $0.03 \%$ and $1.7 \%$, but clinical experience suggests that the actual incidence may be higher ${ }^{3}$.

Symptoms such as pain and edema are known to worsen with menstruation; however, in many clinical series studying endometriosis, cyclical pain was not reported.

In this article, we report a case of abdominal wall scar endometriosis. The definitive diagnosis was determined after histopathological study.

1. Medical doctor, Specialist in the Department of Plastic, Reconstructive, and Aesthetic Surgery, Ankara University Faculty of Medicine, Ankara, Turkey.

2. Medical doctor, Research assistant in the Department of Plastic, Reconstructive, and Aesthetic Surgery, Ankara University Faculty of Medicine, Ankara, Turkey.

3. Medical doctor, Associate professor of Pathology, Department of Pathology, Ankara University Faculty of Medicine, Ankara, Turkey.

4. Medical doctor, Associate professor of Plastic Surgery, Associate Professor of Plastic Surgery, Department of Plastic, Reconstructive, and Aesthetic Surgery, Ankara University Faculty of Medicine, Ankara, Turkey. 


\section{CASE REPORT}

A 41-year-old woman presented to our department because of a mass in the right lower abdominal area for the past 1 year. It was first noted as a lump at the right lower abdomen on the right lateral side of a previous cesarean scar. The mass was associated with persistent pain and was increasing in size.

The patient did not have a history of cyclical pain. However, she had a cesarean section 5 years ago. On examination, we noted a hyperpigmented area at the right lateral side of the cesarean scar, above the mass (Figure 1). The clinical diagnosis of a subcutaneous abdominal wall mass was made and the patient underwent surgery.

The operation performed was a wide local excision. Grossly, it was a black nodular mass with a fibrous cystic formation measuring $4.5 \times 4.5 \times 2.7 \mathrm{~cm}$ in the dermis and subcutaneous tissue.

Microscopically, there were multiple micronodules composed of benign endometrial glands and stroma within the reticular dermis and subcutaneous adipose tissue (Figure 2). There were no malignant cytological features. Immunohistochemistry was performed on tissue sections using a Ventana Automated Immunostainer. The antibodies used included

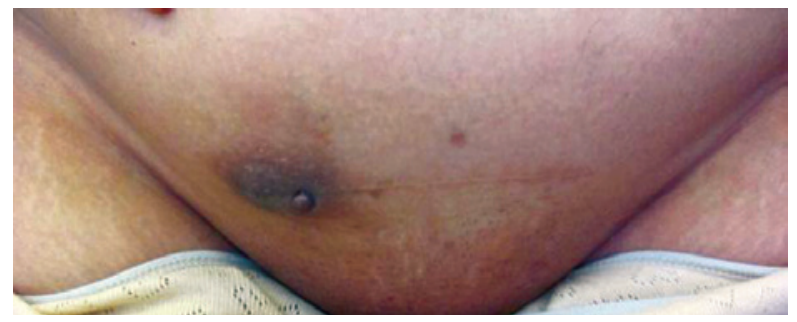

Figure 1 - Cutaneous endometriosis in the cesarean scar.

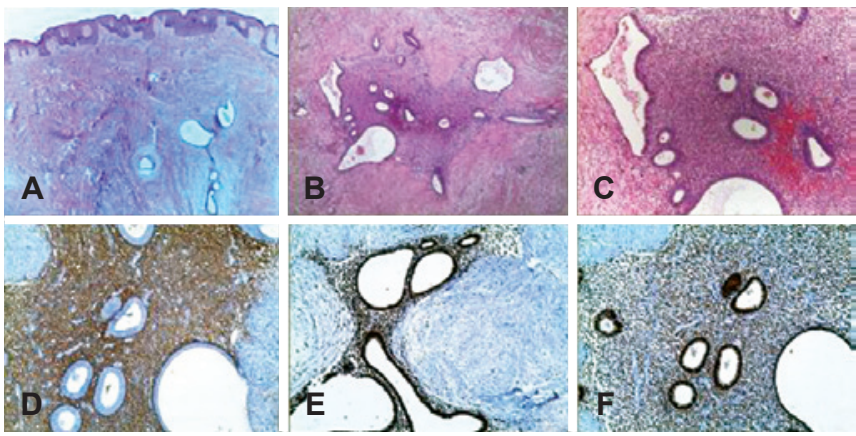

Figure 2 - In $\boldsymbol{A}, \boldsymbol{B}$, and $\boldsymbol{C}$ show multiple micronodules composed of benign endometrial glands and stroma within the reticular dermis and subcutaneous adipose tissue.

In $\boldsymbol{D}, \boldsymbol{E}$, and $\boldsymbol{F}, C D 10$ expression was only noted in the stromal component, whereas ER and PR expressions were noted in the glands and stroma. antibodies for CD10 (56C6, 1:75; Novocastra), progesterone receptor (PR) (SP2, 1:300; Neomarkers), and estrogen receptor (ER) (SP1, 1:100; Cell Marque). Immunohistochemically, CD10 expression was only observed in the stromal component, whereas ER and PR expressions were noted in the glands and stroma.

\section{DISCUSSION}

Cutaneous endometriosis was first described by Villar in $1886^{4}$. A century after Villar, there have been many theories proposed as to the cause of endometriosis. The theory of retrograde menstruation (also called the implantation theory or transplantation theory) is the most commonly accepted theory for the formation of ectopic endometrium ${ }^{5,6}$. It describes the pathological process as an attachment of endometrial debris to the peritoneal surface, which exits the uterus through the fallopian tubes during a woman's menstrual flow. Another explanation, the coelomic metaplasia theory, is based on the fact that coelomic epithelium is the common progenitor of endometrial cells; it is suggested that transformation from one type of cell to the other is possible, perhaps in response to an inflammatory process.

Endometriosis that occurs after operations on the uterus, such as hysterectomy, cesarean section, or myomectomy, supports the transplantation theory. In such cases, it is likely that the endometrial tissue was transplanted to the surgical scar area. In the present case, the patient had a history of cesarean section, but did not have a previous endometriosis complaint, thereby supporting the transplantation theory.

The late onset of symptoms after surgery is a reason for misdiagnosis. The usual clinical presentation is of a parous woman complaining of a painful nodule at the incision site that varies with menses (which thus can prove the functional state of the endometrial tissue outside the uterine cavity). The average period between surgery on the uterus and the onset of symptoms has been reported to be between 4.5 years to 5.72 years in different studies ${ }^{7,8}$. However, some authors reported the onset of symptoms to be as early as 3 months or as late as 10 years. In our patient's case, it was 3.5 years.

Incisional scar endometriosis is a well-defined subject in the gynecology literature but is not well known among plastic surgeons. Preoperatively, most plastic surgeons consider these lesions to be suture granulomas, abscesses, or lipomas. Due to the increased rates of endometriosis and cesarean section, it is essential that we ensure optimal management of scar endometriosis. Surgical excision is both diagnostic and therapeutic in these cases. Wide surgical excision with secure margins is appropriate, and a histopathological examination should be performed, during and after the operation. The depth of cutaneous endometriosis can only be determined at the time of surgery, and total excision is the appropriate 
manner in which to achieve a cure. It is crucial to inform patients preoperatively about the possible placement of a mesh to repair the defect in the rectus sheath. Thus far, there have been some reports of the use of a Prolene mesh following excision of cutaneous endometriosis. In the present case, a suprafascial excision was performed. Malignant transformation of surgical scar endometriosis is rare; however, we should be aware of the possibility because it has been reported ${ }^{9}$.

Educating all types of physicians, including general practitioners, is important to help in the diagnosis and surgical treatment of this rare condition. Moreover, plastic surgeons should consider this condition in female patients who present with a postoperative abdominal wall mass at the incision site.

\section{REFERENCES}

1. Bulletti C, Coccia ME, Battistoni S, Borini A. Endometriosis and infertility. J Assist Reprod Genet. 2010;27(8):441-7.
2. Agarwal A, Fong YF. Cutaneous endometriosis. Singapore Med J. 2008; 49(9):704-9.

3. Upadhyaya P, Karak AK, Sinha AK, Kumar B, Karki S, Agarwal CS Abdominal wall endometriosis. JNMA J Nepal Med Assoc. 2010; 49(178):158-60.

4. Michovitz M, Baratz M, Stavorovsky M. Endometriosis of the umbilicus. Dermatologica. 1983;167(6):326-30.

5. van der Linden PJ. Theories on the pathogenesis of endometriosis. Hum Reprod. 1996;11 Suppl 3:53-65.

6. Evian Annual Reproduction (EVAR) Workshop Group 2010, Fauser BC, Diedrich K, Bouchard P, Domínguez F, Matzuk M, Franks S, et al. Contemporary genetic technologies and female reproduction. Hum Reprod Update. 2011;17(6):829-47.

7. Gunes M, Kayikcioglu F, Ozturkoglu E, Haberal A. Incisional endometriosis after cesarean section, episiotomy and other gynecologic procedures. J Obstet Gynaecol Res. 2005;31(5):471-5.

8. Dragoumis K, Mikos T, Zafrakas M, Assimakopoulos E, Stamatopoulos $\mathrm{P}$, Bontis J. Endometriotic uterocutaneous fistula after cesarean section. A case report. Gynecol Obstet Invest. 2004;57(2):90-2.

9. Terada S, Miyata Y, Nakazawa H, Higashimori T, Arai T, Kikuchi Y, et al. Immunohistochemical analysis of an ectopic endometriosis in the uterine round ligament. Diagn Pathol. 2006;1:27.
Correspondence to:
Emrah Aslan

Ankara University, Faculty of Medicine, Department of Plastic Reconstructive and Aesthetic Surgery 06590 - Cebeci, Ankara, Turkey

E-mail: dr_aslan@windowslive.com 